\title{
Propaganda de medicamentos no contexto do SUS e no ensino médico: por que discutir?
}

Advertising of medications within the context of the Brazilian Health System (SUS) and medical education: why discuss it?

Propaganda de fármacos en el contexto de lo Sistema Unico de Salud brasileño (SUS)

y en la enseñanza de medicina

Neilton Araujo de Oliveira ${ }^{1}$

O acesso a medicamentos é parte integrante do direito à saúde, consagrado no texto constitucional (CF, 1988), bem como em diversos outros instrumentos legais, e também um componente fundamental da atenção à saúde, representando hoje um dos maiores desafios da concretização desse direito, considerada a integralidade da saúde.

Além de contribuir com impostos para financiar o sistema de saúde, as famílias gastam uma parcela considerável de sua renda com medicamentos e outros insumos e serviços de saúde, muitas vezes sacrificando o atendimento de outras necessidades elementares. O medicamento não é uma mercadoria comum e, sendo essencial à saúde e à vida das pessoas, deveria ser mais acessível para toda a população, em cumprimento ao direito universal do SUS. A produção, a distribuição, a propaganda, a venda e a dispensação dos medicamentos dependem de instrumentos e condições legais específicas.

No presente debate - cuja questão central é a propaganda de medicamentos em ambientes de ensino e tem o artigo de Marisa Palácios, Sérgio Rego e Maria Helena Lino como proposta -, estão implícitos outros temas relevantes para o sistema de saúde e para a qualidade de vida da população. Esses temas dizem respeito tanto ao processo de construção do SUS e à educação médica, ou à educação em saúde, como também à dimensão ética e da regulação em saúde e, mais especificamente, a regulação da propaganda de medicamentos. A grande contribuição desse artigo, no que os autores foram muito competentes, refere-se aos elementos fundamentais, oportunos e atuais, relativos ao debate sobre propaganda de medicamentos no ambiente de ensino, contemplando, entre outros, os aspectos éticos.

Esta discussão vem assumindo crescente relevância e deve ser foco de um debate cada dia mais intenso, no contexto da globalização e do processo de desenvolvimento do país. Quando se analisa o sistema de saúde, seu processo de construção e os enormes desafios que o SUS tem enfrentado em diferentes aspectos, sem dúvida nenhuma a questão do (sub)financiamento do setor aparece como fator determinante de outras dificuldades, em especial a dos medicamentos. Mas o que mais nos interessa aqui é a propaganda de medicamentos no ambiente de ensino (especialmente o da medicina). Essa propaganda - no sentido da publicidade e da promoção de vendas - é também, no presente momento, um

${ }^{1}$ Médico. Universidade Federal do Tocantins. 109 Norte, Av. NS 15 , ALCNO 14, Bloco IV, sala 205. Palmas, TO $77.001-090$ neilton@uft.edu.br 
assunto que está no centro de discussão de dois sujeitos institucionais e importantes agentes reguladores, o Conselho Federal de Medicina (CFM) e a Agência Nacional de Vigilância Sanitária (Anvisa). No CFM, a questão envolve fundamentalmente a conduta médica e é ao médico que se dirigem suas decisões e recomendações éticas, calcadas numa "máxima" recente de que o médico não é garoto propaganda e não precisa nem deve receber brindes da indústria e de laboratórios farmacêuticos. Na Anvisa, os intensos esforços para o aprimoramento da regulamentação da propaganda de medicamentos envolvem diversos atores, mas são prioritariamente endereçados a empresas ligadas à produção e ao comércio de medicamentos, bem como à mídia em suas diferentes manifestações e, por extensão, à população em geral. Portanto, mais do que valioso e muito oportuno, o artigo de Marisa Palácios, Sérgio Rego e Maria Helena Lino, com riqueza de dados, análises e informações, traz novas proposições para o debate e importantes subsídios concretos para a regulação e o controle da propaganda de medicamentos.

É importante ressaltar que, ao falar em "proibir a propaganda de medicamentos no ambiente de ensino", Palácios, Rego e Lino não negam a legitimidade da propaganda, e penso que isso não deva ser objeto de uma lei específica: trata-se antes de enfrentar, aberta e corajosamente, esse debate no próprio ambiente acadêmico, e cada instituição de ensino, democraticamente, adotar, sim, regras éticas e claras de limites e restrição a patrocínio e propaganda de laboratórios farmacêuticos que, a meu juízo, dificultam e até mesmo impedem a formação do estudante de medicina calcada em conhecimentos científicos e éticos. Tal medida já vem sendo adotada com êxito há bastante tempo por diversas entidades médicas e de representação do setor saúde em seus eventos científicos, quando, para manter o rigor científico e ampla e livre a discussão técnica, rejeitam propaganda ou patrocínio da indústria farmacêutica.

Quando se fala em regulação, é salutar defender a auto-regulação, mas esta é ainda muito tímida e ineficaz, demandando, portanto, monitoramento e vigilância cotidiana por parte dos órgãos públicos responsáveis por essa tarefa, sobretudo contra a propaganda abusiva ou enganosa.

Outro aspecto que me chamou a atenção no texto de Palácios, Rego e Lino foi o destaque dado ao confronto entre, de um lado, o que as aulas de bioquímica e farmacologia tentam promover na formação dos alunos e, de outro, o que o "propagandista", com informações objetivas e sintéticas, vêm prometendo em termos de cura ou de controle de doenças. Nesse sentido, ultimamente venho com freqüência debatendo a influência da indústria e da propaganda de medicamentos na formação médica e tenho escutado invariavelmente o relato dos professores de farmacologia sobre representantes dos diversos laboratórios farmacêuticos que dificilmente têm aceitado convites para participar de eventos programados por essa disciplina, num comportamento muito diferente de quando são chamados para eventos de diversas outras especialidades médicas.

Estou convencido de que não se trata de sobrecarga de compromissos desses representantes de laboratórios nem de acaso, mas de evitar o possível confronto entre a postura crítica, baseada em raciocínio e conhecimento científico, da disciplina de farmacologia e a postura dos propagandistas, ancorada apenas em promessas "(nem sempre confiáveis) relacionando um produto a uma doença". Esta questão merece ser considerada um tema prioritário a ser debatido e, assim, investigado e esclarecido. Enquanto tecemos estas reflexões aqui, está em discussão na Diretoria Colegiada da Anvisa, fruto de uma consulta pública, a revisão da RDC 102/2000 com o objetivo de atualizar e aprimorar a regulamentação de propaganda de medicamentos. De início, modificam-se e ampliam-se alguns conceitos que, consoantes ao novo Regulamento, serão aplicados pela Anvisa à "propaganda, publicidade, informação e outras práticas cujo objetivo seja a divulgação ou promoção para a comercialização de medicamentos de produção nacional ou estrangeira" (minuta da revisão 2008, da RDC 102/2000, em discussão). Assim "promoção" e "propaganda/publicidade" passarão a ser apenas "propaganda/publicidade", o que se caracteriza como "o conjunto de técnicas e atividades de informação e persuasão com o objetivo de divulgar conhecimentos, tornar mais conhecido e/ou prestigiado determinada marca ou produto, colocados à disposição no mercado, visando a exercer influência sobre o público por meio de ações que objetivem promover e/ou induzir a prescrição, dispensação, aquisição e utilização de medicamento" (minuta da revisão 2008, da RDC 102/2000, em discussão). 
Diante da abordagem que acertadamente adotaram Palácios, Rego e Lino ao explorar os diversos tipos e os diferentes espaços de regulação e regulamentação da propaganda de medicamentos em que destacam aspectos jurídico-legais, éticos, didático-pedagógicos e de participação social, entre outros -, pressupõe-se que devem aumentar a disposição e o compromisso, por parte das diferentes instituições e de outros sujeitos coletivos, quanto à análise circunstanciada desse tema para, ao final, cada uma na sua especificidade e algumas em ações coletivas, assumirem aquilo que lhes compete como sujeitos participantes de um processo de desenvolvimento democrático e civilizatório, com ênfase na saúde e na qualidade de vida da população.

Especialmente no campo da educação médica, esse debate precisa envolver o setor de serviços de saúde e do SUS e outros setores sociais e mobilizar movimentos popular-comunitários, condição importante para o avanço no processo de mudança na educação médica brasileira.

Finalmente, penso que essa visão utilitarista que tem a indústria farmacêutica dos ambientes de ensino para propagandear medicamentos e influenciar a prescrição de atuais e futuros médicos contribui para dificultar uma necessária cooperação entre indústria e academia para o desenvolvimento de pesquisas e de novos conhecimentos. Essa possível relação de colaboração, creio, ainda é cercada de muito preconceito de ambas as partes e, nesse sentido, a conjugação de esforços desses dois importante sujeitos, articulados e com envolvimento e participação social, numa relação franca e ética de colaboração mútua, em última análise, representará uma possibilidade concreta de se alavancar e acelerar a busca de novos conhecimentos e benefícios para a saúde da população, para o processo de desenvolvimento do país e para a sociedade em geral.

\section{Referências}

PALÁCIOS, M.; REGO, S.; LINO, M.H. Promoção e propaganda de medicamentos em ambientes de ensino: elementos para o debate. Interface - Comunic., Saúde, Educ. v.12, n.27, p.895-908, 2008 